\title{
Intra-operative trans-cystic indocyanine green (ICG) cholangiography: a high-sensitive method to identify bile leakage after hepatic resection
}

\author{
Piera Leon, Fabrizio Panaro \\ Division of HBP Surgery and Transplantation, Department of Surgery, St. Eloi Hospital, Montpellier University Hospital-School of Medicine, \\ Montpellier, France \\ Correspondence to: Fabrizio Panaro, MD, PhD. Professor of Surgery, Division of GI Surgery and Transplantation, Department of Surgery, Hôpital \\ Saint Eloi, CHU-Montpellier, 80 Av. Augustin Fliche, 34295 Montpellier, France. Email: f-panaro@chu-montpellier.fr.
}

Submitted May 13, 2019. Accepted for publication May 30, 2019.

doi: 10.21037/hbsn.2019.12.08

View this article at: http://dx.doi.org/10.21037/hbsn.2019.12.08

Liver resections are more and more performed worldwide. While mortality for hepatic surgery is decreasing over the time, morbidity is still high and mostly affected by bile leak which remain the Achilles' heel of this type of surgery. Indeed, still $3 \%$ to $33 \%$ of patients present bile leak in the post-operative period (1).

Bile leakage is a really serious complication leading to intrabdominal collections, sepsis, immunity dysregulation and liver function impairment. Nevertheless, it greatly affects quality of life, prolongs hospital stay and inevitably increases health costs $(1,2)$.

The extend and type of liver resection are both related to an increased risk of bile leak. Moreover, bile ducts resection and bilioenteric anastomoses are evenly related to the occurrence of this complication. Conversely, methods of liver transection do not seem to significantly impact the incidence of postoperative biliary leaks $(1,3)$.

In order to prevent bile leak, the meticulous control of the cut surface of the liver has been advocated. The intraoperative identification and ligation of any leaking bile duct is mandatory to limit postoperative complications' occurrence. The intra-operative trans cystic injection of socalled revealing solution is the preferred method to identify bile leak $(1,3,4)$.

As far, several intraoperative tests have been employed. Saline, methylene bleu, fat emulsion and indocyanine green (ICG) have been used.

Saline trans-cystic injection, which is simple, cheap and reproductible, does not seem to decrease biliary complications' rate $(1,4)$.
Colored solutions as methylene bleu are apparently more sensitive than saline in detecting leaking ducts but they are limited by the non-repeatability of the test.

Fat emulsion, also called the white dye, showed a slightly higher identification rate of bile leak over saline; however, improvements on bile leak prevention are still poor, presumably due to its viscosity (5).

An impressing and even promising result come from the intrabiliary injection of ICG dye followed by fluorescent imaging (6-9).

As published already 8 years ago by Sakaguchi et al. (6) and then by Kaibori et al. (7), indeed, direct fluorescent cholangiography showed high detection rate for small bile leaks and low postoperative complications rate. Besides, these results were obtained using the "old technology" in fluorescent imaging.

The ICG dye $\left(0.05 \mathrm{mg} / \mathrm{Kg}\right.$ ICG-Pulsion ${ }^{\circledR}$, Munich, Germany) was injected through a trans-cystic catheter in the biliary tree, the common bile duct was then clamped distal to the catheter and near-infra-red (NIR) fluorescent imaging was performed (using Olympus ${ }^{\circledR}$ technology, Tokyo, Japan).

As known, the fluorescent cholangiography bears powerful enhancement of tissues contrast, offering an augmented visualization of the biliary structures. It allows the fine detection of small leaking ducts, being able to assess the entire cut surface of the liver for $5 \mathrm{~mm}$ in depth. Furthermore, the ICG fluorescence, showing all the superficial bile ducts $(<5 \mathrm{~mm})$ on the cut surface of the liver (Figure 1), focus the attention of the surgeon on 


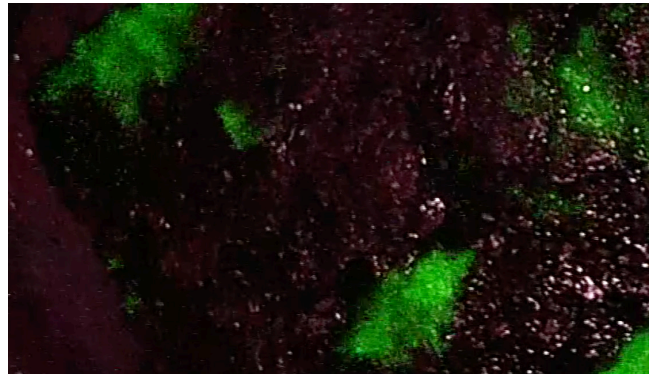

Figure 1 Bile ducts visualization on the cut surface of the liver on ICG fluorescent imaging. ICG, indocyanine green.
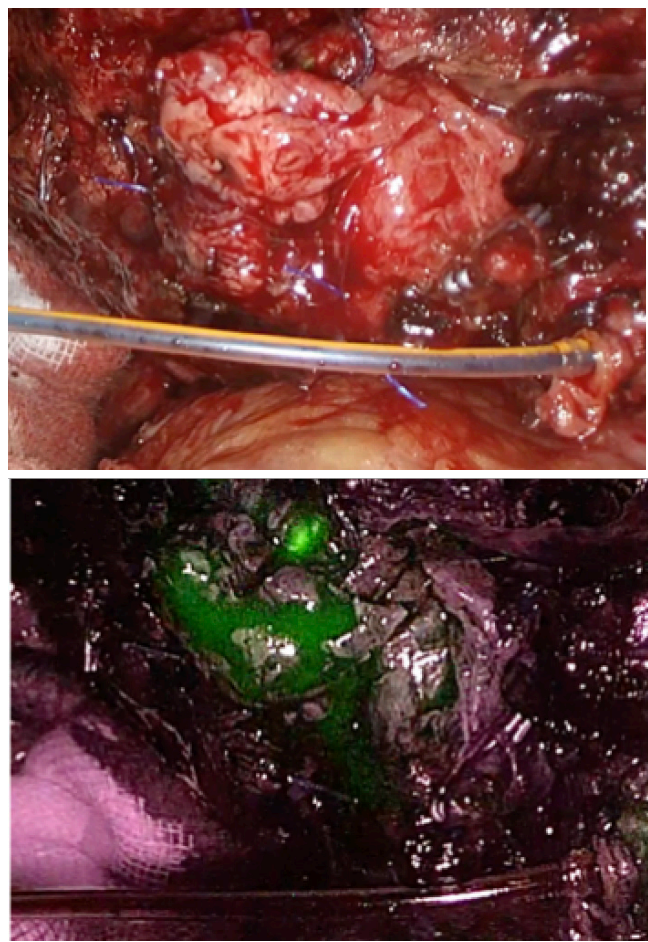

Figure 2 Comparison between methylene blue test (A) and ICG fluorescence (B) on the same cut surface of the liver after performing right hepatectomy. Bile leak was easily detectable when ICG with NIR fluorescence are used (B). ICG, indocyanine green; NIR, .near-infra-red.

potential points of bile leak.

This intrabiliary injection of ICG is clearly advantageous over the intravenous one, mainly performed, for several reasons: first for time coordination (injection/NIR imaging almost directly), simplicity, rapidity and for the repeatability of the test. Moreover, the absence of ICG dye imbuing the liver parenchyma leads to high-contrast visualization and allergic reaction, already rare, are even less probable.

In our experience, today, fluorescent ICG cholangiography is superior in detecting bile leaks on the transected hepatic surface compared to methylene bleu (Figure 2). Methylene blue performed first (1 fl/20 mL of injected solution), in this particular case of right hepatectomy, did not objective any bile leaks, which were later clearly identified using ICG dye injection and fluorescence.

Moreover, fluorescent ICG cholangiography, performed after the intrabiliary injection of the dye, is also applicable in many other complexes situations to obtain the intraoperative identification of bile structures: for example, in case of complex acute cholecystitis, lymphadenectomy of the hepatic pedicle in multi-operated patients or undergone recurrent cholangitis and/or pancreatitis and/or biliary stenting (10).

Fluorescent ICG cholangiography requires special equipment to be realized and this can be very limiting. However, nowadays this technology is much more easily available than in the past, in many operating rooms worldwide, as the field of fluorescent imaging is enormously expanding $(1,8,9)$.

These promising results of intrabiliary use of ICG with fluorescent imaging are still preliminary, coming from small and not randomized series. More studies have to be designed to evaluate the direct application of ICG and fluorescence and to assess sensitivity of the method.

\section{Acknowledgments}

Funding: None.

\section{Footnote}

Conflicts of Interest: Both authors have completed the ICMJE uniform disclosure form (available at https://hbsn.amegroups. com/article/view/10.21037/hbsn.2019.12.08/coif). FP serves as an unpaid editorial board member of Hepatobiliary Surgery and Nutrition. PL has no conflicts of interest to declare.

Ethical Statement: The authors are accountable for all aspects of the work in ensuring that questions related to the accuracy or integrity of any part of the work are appropriately investigated and resolved.

Open Access Statement: This is an Open Access article distributed in accordance with the Creative Commons 
Attribution-NonCommercial-NoDerivs 4.0 International License (CC BY-NC-ND 4.0), which permits the noncommercial replication and distribution of the article with the strict proviso that no changes or edits are made and the original work is properly cited (including links to both the formal publication through the relevant DOI and the license). See: https://creativecommons.org/licenses/by-ncnd/4.0/.

\section{References}

1. Kapoor S, Nundy S. Bile Duct Leaks from the Intrahepatic Biliary Tree: A Review of Its Etiology, Incidence, and Management. HPB Surg 2012. doi:10.1155/2012/752932.

2. Panaro F, Hacina L, Bouyabrine $\mathrm{H}$, et al. Risk factors for postoperative bile leakage: a retrospective single-center analysis of 411 hepatectomies. Hepatobiliary Pancreat Dis Int 2016;15:81-6.

3. Nagano $Y$, Togo S, Tanaka K, et al. Risk factors and management of bile leakage after hepatic resection. World J Surg 2003;27:695-8.

4. Ijichi M, Takayama T, Toyoda H, et al. Randomized trial of the usefulness of a bile leakage test during hepatic resection. Arch Surg 2000;135:1395-400.

Cite this article as: Leon P, Panaro F. Intra-operative transcystic indocyanine green (ICG) cholangiography: a highsensitive method to identify bile leakage after hepatic resection. HepatoBiliary Surg Nutr 2020;9(2):260-262. doi: 10.21037/ hbsn.2019.12.08
5. Li J, Malagó M, Sotiropoulos GC, et al. Intraoperative application of "white test" to reduce postoperative bile leak after major liver resection: results of a prospective cohort study in 137 patients. Langenbecks Arch Surg 2009;394:1019-24.

6. Sakaguchi T, Suzuki A, Unno N, et al. Bile leak test by indocyanine green fluorescence images after hepatectomy. Am J Surg 2010;200:e19-23.

7. Kaibori M, Ishizaki M, Matsui K, et al. Intraoperative indocyanine green fluorescent imaging for prevention of bile leakage after hepatic resection. Surgery 2011;150:91-8.

8. Ishizawa T, Tamura S, Masuda K, et al. Intraoperative fluorescent cholangiography using indocyanine green: a biliary road map for safe surgery. J Am Coll Surg 2009;208:e1-4.

9. Ishizawa T, Saiura A, Kokudo N, et al. Clinical application of indocyanine green-fluorescence imaging during hepatectomy. Hepatobiliary Surg Nutr 2016;5:322-8.

10. Graves C, Ely S, Idowu O, et al. Direct Gallbladder Indocyanine Green Injection Fluorescence Cholangiography During Laparoscopic Cholecystectomy. J Laparoendosc Adv Surg Tech A 2017;27:1069-73. 